\title{
The Dark Side of Conscientiousness
}

\author{
Adrian Furnham \\ Department of Psychology, University College London, London, UK \\ Email: a.furnham@ucl.ac.uk
}

How to cite this paper: Furnham, A. (2017). The Dark Side of Conscientiousness. Psychology, 8, 1879-1893. https://doi.org/10.4236/psych.2017.811122

Received: August 17, 2017

Accepted: September 26, 2017

Published: September 29, 2017

Copyright $\odot 2017$ by author and Scientific Research Publishing Inc. This work is licensed under the Creative Commons Attribution International License (CC BY 4.0).

http://creativecommons.org/licenses/by/4.0/

\begin{abstract}
This paper reports on two studies, each with large adult populations, which look at Dark-Side correlates (subclinical Personality Disorders) of two different measures of Trait Conscientiousness. In the first study, 5300 British adults completed the Prudence scale of the Hogan Personality Inventory (HPI) as well as the Hogan Development Survey (HDS), which measures Dark-Side traits. Correlation and regression results confirmed many of the associations between the seven facets of the Prudence scale and the Dark Side traits. Results showed that people who score high on Excitable, Mischievous and Imaginative reported low scores, while those who scored high on Diligent reported high scores on Prudence and its facets. In the second study, 6700 British adults completed the NEO-PI-R Conscientiousness Scale with six facet scores as well as the HDS. Regressions showed a similar pattern: people scoring high on Bold and Diligent, and low on Excitable and Cautious reported higher Conscientiousness. Similarities and differences in the findings for the two studies are considered. Paradoxically Conscientiousness is negatively associated with those Dark Side traits that are correlated with leadership emergence. Limitations of these studies are discussed.
\end{abstract}

\section{Keywords}

Dark Side, Big Five, Prudence, Concientiousness, Learning Approach

\section{Introduction}

This paper considers the relation between Dark Side traits (Bollaert, \& Petit, 2010) and different measures of trait Conscientiousness (C). There is a considerable academic literature on $\mathrm{C}$ which suggests that it is associated with a wide range of positive outcomes such as educational and occupational success, health, longevity, and social adaptation (MacCann, Duckworth, \& Roberts, 2009). Conscientious people are persevering, refrain from procrastination and are industrious. Nearly all of the facets of C, namely industriousness, order, self-control, 
traditionalism, responsibility and virtue could be seen to be positive characteristics (Roberts, Chernyshenko, Stark, \& Goldberg, 2005).

Yet as Nettle (2006) has argued there can be a negative side to all traits and that $\mathrm{C}$ can be associated with obsessionality, perfectionism, rigidity and slowness to respond. The high $\mathrm{C}$ person may be over conventional and traditionalist, so rejecting change and innovation as well as over-cautious. They therefore may be less successful at work and unlikely to reach high managerial positions (Hogan, 2007). Indeed Carter, Dalal, Boyce et al. (2014) demonstrated that there is a curvilinear relationship between $\mathrm{C}$ and job performance

This paper reports two studies with different measures of $\mathrm{C}$, in an attempt to replicate findings.

One scale labelled Prudence is taken from the HPI with seven empirically derived facet scales, while the other is labelled Conscientiousness and which taken from the NEO-PI-R and has six non-empirically derived scales. Correlations between these two measures are in the region of $r=0.40$ which suggests some significant differences between the way the two dimensions are conceived (Hogan \& Hogan, 2007).

Various studies have suggested that, paradoxically, subclinical levels of particular dysfunctional "dark side" traits may, at times and in specific work contexts, be beneficial to success and career progression (Furnham, 2010). There has been a considerable interest in the dark triad which measures sub-clinical Machiavellianism, Narcissism and Psychopathy (for review see Furnham, Richards \& Paulhus, 2013). In this study we used the Hogan Developmental Survey (HDS) (Hogan \& Hogan 2009) to measure dark-side traits and accept the definition of dark-side as specified by the test. Dark-side variables are considered as dysfunctional dispositions that reflect distorted beliefs about others that emerge when people encounter stress or stop considering how their actions affect others. Over time, these dispositions may become associated with a person's reputation and can impede job performance and career success. They are essentially self-defeating expressions of normal personality. The DSM-5 (American Psychiatric Association, 2013: p. 647) makes this same distinction between behavioral traits and disorders-self-defeating behaviors, such as those predicted by the HDS, come and go depending on the context. In contrast, personality disorders are enduring and pervasive across contexts.

This study is concerned with the dark-side or down-side of high C. Clearly Obsessive Compulsive Disorder (OCD) and Obsessive Compulsive Personality Disorder (OCPD) is conceived of in terms of pathological levels of $\mathrm{C}$, but this paper also explores the relationship between the other Dark Side factors (as defined above) and C (Koutoufa \& Furnham, 2014).

\subsection{The Dark Side Traits and Conscientiousness}

There have been various attempts to integrate "normal" and "abnormal" personality structure (Widiger, 2011; Widiger, Costa, \& McCrae, 2001). Widiger et al. (2001) provided an important theoretical analysis of the relationship between 
personality disorders and the Big Five, at both Domain and Facet level. A table in that chapter indicates the hypothetical association between the possible $30 \mathrm{fa}$ cets of the well-established and accepted NEO-PI-R (Costa \& McCrae, 1992) and OCD. In all, one Neuroticism (N3 Depression), one Extraversion (E3 Assertiveness) and four Conscientious facets (H2 Order; H3 Dutifulness; H4 Achievement Striving, and H6 Deliberation) were thought to have a theoretically strong positive association with OCD. Similarly one Extraversion (O1: Warmth), two Openness (O3 Feelings; O6 Values) and two Agreeableness (A3 Altruism and A4 Compliance) facets were hypothesised to have a strong negative correlation with OCD.

This speculative work was updated in an important review by Samuel and Widiger (2008) who combined the data from 16 studies with a total $\mathrm{N}$ of 3207. Most of the participants were students (12 groups) and some outpatients. Further, they had completed very different personality disorder instruments, yet nearly always the same personality instrument (NEO-PI-R) was used (as in this study). They analysed their results at both the domain and facet level and compared their results to an earlier and similar study by Saulsman and Page (2004). They showed that OCPD was correlated positively with Neuroticism $(r=0.18)$ and Conscientiousness $(r=0.24)$. What was most interesting about the facet level analysis was that OCPD was correlated with all six Conscientiousness facets ( $r$ between 0.19 and 0.25 ). Four other correlations were $r>0.10$ and they were N1. Anxiousness (0.16), N2. Angry Hostility (0.10), N3. Self-Consciousness (0.13) and E5. Excitement seeking (-0.12). More recently Bastiaansen, Rossi, Schotte and De Fruyt (2011) also did a review and suggest there are five facets that are (very) highly positively associated with OCPD: E3, C1, C2, C3 and C4 and two that is highly negatively associated with OCPD: O6 and A4. Bastiaansen, Rossi and De Fruyt (2012) reviewed five papers that suggested overlap between the PDS and C facets. Some suggested that facets of $\mathrm{C}$ would be related positively to Narcissistic PD but negatively with Borderline, Anti-Social and Dependent, but very clearly associated with OCPD.

\subsection{Measuring the Dark Side: The HDS}

The Hogan "dark side" measure is now extensively used in organisational research and practice to measure personality disorders in the "normal population" (Carson, Shannock, Heggestad, Andrew, Pugh, \& Walter, 2012; De Fruyt et al., 2009; Furnham \& Crump, 2005). The Hogan Development Survey (HDS) was explicitly based on the DSM-IV-TR Axis II Personality Disorder descriptions, but it was not developed for the assessment of all DSM-IV-TR disorders (American Psychiatric Association, 2013). The HDS contains 168 true/false items that assess dysfunctional interpersonal themes. These dysfunctional dispositions reflect one's distorted beliefs about others that emerge when people encounter stress or stop considering how their actions affect others. It does not measure personality disorders, which are manifestations of mental disorder. In- 
stead, the HDS assesses self-defeating expressions of normal personality. The HDS focuses only on the core construct of each disorder from a dimensional perspective (Hogan \& Hogan, 2001: p. 41). Fico, Hogan and Hogan (2000) report coefficient alphas between 0.50 and 0.70 with an average of 0.64 and test-retest reliabilities $(n=60)$ over a three-month interval ranging from 0.50 to 0.80 , with an average of 0.68 . Various relatively small scale studies have used the HDS and have shown it to be a robust, reliable and valid instrument (De Fruyt et al., 2009; Furnham \& Crump, 2005; Rolland \& De Fruyt, 2003).

The HDS labels each dimension for low to high as "no risk, low risk, moderate risk and high risk". The idea is that high scores can be an indicator of business derailment, because under pressure a successful and functioning person may resort to being over-diligent described as "conscientious, perfectionistic and hard to please". This is seen to have behavioural implication around flexibility with rules and procedures, the prioritization of work, delegation and working without explicit instructions. Those whose diligence scores are in the high risk zone have difficulties with ambiguity, adaptability and delegating downward. Very few diligent people are diagnosed OCPD and can function at high levels. Indeed for certain jobs like quality control and internal audit diligence, as defined by this measure, is highly valued.

The central research question in both studies is the relationship between the eleven dark-side measures from the HDS and domain and facets scores from two different measures of Conscientiousness. In this sense it is an attempt to check the generalisability of the findings over two instruments. In both studies we had large populations of working adults around 40 years old but where males outnumbered females around four to one.

\section{Study 1}

This study uses the Domain variable Prudence and its seven facets as the criterion variable (see Table 1 for names of each). Based on the previous literature it was hypothesised that Prudence, measured at the Domain and Facet level would be negatively correlated with Excitable, Mischievous, Bold and Colourful but positively correlated with Diligent and Dutiful.

\subsection{Method}

\subsubsection{Participants}

In total 6957 British working adults took part in this study of which 1493 were females and 5464 males. Their mean age was 42.36 years ( $S D=7.12$ years) with the range being between 23 and 65 years. They were nearly all (over 95\%) graduates and in middle class occupations with English as their mother tongue. Nearly $80 \%$ (79.8\%) described themselves as white British. All were in full time work.

\subsubsection{Materials}

Hogan Personality Inventory (HPI) (Hogan \& Hogan, 2007)-This 206 item measure has two types of scales: seven personality traits and six criterion scores. 
Table 1. Correlations between demographic, Prudence and dark side variables $(\mathrm{N}=6512)$.

\begin{tabular}{ccccccccccc}
\hline & Age & Gender & Prudence & Moralistic & Mastery & Virtuous & $\begin{array}{c}\text { Not } \\
\text { Autonomous }\end{array}$ & $\begin{array}{c}\text { Not } \\
\text { Spontaneous }\end{array}$ & $\begin{array}{c}\text { Impulse } \\
\text { Control }\end{array}$ & $\begin{array}{c}\text { Avoids } \\
\text { Trouble }\end{array}$ \\
\hline Age & 1 & -0.05 & 0.00 & -0.02 & -0.00 & -0.01 & 0.01 & 0.01 & 0.01 & -0.01 \\
Gender & -0.05 & 1 & 0.02 & 0.02 & 0.07 & 0.02 & 0.03 & -0.04 & 0.01 & 0.01 \\
Excitable & -0.09 & 0.04 & -0.36 & -0.31 & -0.12 & -0.38 & 0.01 & -0.07 & -0.16 & -0.28 \\
Sceptical & -0.15 & -0.04 & -0.29 & -0.10 & 0.04 & -0.22 & -0.14 & -0.07 & -0.17 & -0.39 \\
Cautious & -0.06 & 0.15 & -0.09 & -0.17 & -0.06 & -0.15 & 0.09 & -0.01 & 0.05 & -0.08 \\
Reserved & 0.01 & -0.10 & -0.22 & -0.13 & -0.10 & -0.13 & -0.29 & -0.03 & -0.02 & -0.16 \\
Leisurely & -0.09 & -0.01 & -0.17 & -0.07 & 0.03 & -0.07 & -0.07 & -0.11 & -0.11 & -0.21 \\
Bold & -0.10 & -0.06 & -0.06 & 0.15 & 0.13 & 0.00 & -0.02 & -0.08 & -0.18 & -0.17 \\
Mischievous & -0.08 & -0.11 & -0.39 & 0.02 & -0.04 & -0.04 & -0.14 & -0.27 & -0.54 & -0.31 \\
Colourful & -0.07 & -0.05 & -0.17 & 0.03 & -0.03 & -0.07 & 0.07 & -0.11 & -0.30 & -0.13 \\
Imaginative & -0.10 & -0.04 & -0.32 & -0.03 & -0.03 & -0.06 & -0.10 & -0.20 & -0.35 & -0.32 \\
Diligent & -0.08 & 0.02 & $\mathbf{0 . 3 3}$ & $\mathbf{0 . 2 1}$ & $\mathbf{0 . 4 8}$ & 0.12 & -0.03 & 0.20 & 0.21 & 0.03 \\
Dutiful & $-\mathbf{0 . 1 4}$ & 0.05 & 0.15 & -0.02 & 0.10 & 0.10 & 0.20 & 0.06 & 0.09 & 0.05 \\
\hline
\end{tabular}

a. Correlation $>0.20$ are shown in bold. Correlations of $r>0.05$ are $p<0.001$.

The seven personality traits assessed are: adjustment, ambition, sociability, interpersonal sensitivity, prudence, inquisitive, learning approach. Prudence is defined as the degree to which a person is conscientious, conforming, dependable, detail oriented, planful and rule following. It has seven empirically derived subscales (examples of an item is in brackets)

1) Moralistic: Adhering strictly to conventional values (I always practice what I preach).

2) Mastery: Being hard-working (I strive for perfection in everything I do).

3) Virtuous: Being perfectionistic (I do my job as well as I possibly can).

4) Not Autonomous: Concern about others' opinions of oneself (Other people's opinions of me are important).

5) Not Spontaneous: Preference for predictability (I always know what I will do tomorrow).

6) Impulse Control: Lack of impulsivity (I rarely do things on impulse)

7) Avoids Trouble: Professed probity (When I was in school I rarely gave the teachers any trouble).

The manual reports alphas for all the scale over 0.80 and test-retest reliability varying between 0.69 and 0.87

Hogan Development Survey (Hogan \& Hogan, 2009) consists of 154 items that are concerned with how the respondent typically interacts with family, friends and co-workers. There are 11 dimensions, each with 14 questions. Respondents are requested to "agree" or "disagree" with the items. Higher scores on the scales correspond to an increased risk on specific interpersonal problems in the workplace. The HDS has been cross-validated with the MMPI personality disorder scales as well as "normal traits" (Furnham \& Crump, 2005). The alpha 
for the scale was 0.71 .

\subsubsection{Procedure}

Participants were tested by a British based psychological consultancy over a 10 year period. Each participant was given personal feedback on their score. They took this test as part of an assessment exercise, run by an external psychological consultancy.

\subsection{Results}

In both studies the latest SPSS package was used to analyse the data.

Table 1 shows the correlations between the demographic, dark-side and Prudence variables. The dark side pattern of results is relatively clear, both at the domain and facet level. The results suggested that most dark side factors, particularly Excitable, Mischievous and Imaginative were negatively, and Diligent positively associated with Prudence. However the facet analysis indicated numerous differences. Thus correlations between the dark side variables and Moralistic and Impulse Control were very different.

A series of regressions were then run. First age and sex were entered and then the 11 dark side factors (see Table 2). All regressions, both on the dimensional and facet level of prudence, were significant. On the dimensional level, $45 \%$ of the variance could be explained, whereas regressions with prudence facets,

Table 2. Regressions with the seven subscales as the criterion scale and demographics and the 12 Dark Side scores as the predictor scales. Beta $>0.10$ are highlighted in Bold. Beta's $>0.04, p<0.001$.

\begin{tabular}{|c|c|c|c|c|c|c|c|c|c|c|c|c|c|c|c|c|}
\hline & \multicolumn{2}{|c|}{ Prudence } & \multicolumn{2}{|c|}{ Moralistic } & \multicolumn{2}{|c|}{ Mastery } & \multicolumn{2}{|c|}{ Virtuous } & \multicolumn{2}{|c|}{$\begin{array}{c}\text { Not } \\
\text { Autonomous }\end{array}$} & \multicolumn{2}{|c|}{$\begin{array}{c}\text { Not } \\
\text { Spontaneous }\end{array}$} & \multicolumn{2}{|c|}{$\begin{array}{l}\text { Impulse } \\
\text { Control }\end{array}$} & \multicolumn{2}{|c|}{$\begin{array}{l}\text { Avoids } \\
\text { Trouble }\end{array}$} \\
\hline & Beta & $\mathrm{t}$ & Beta & $t$ & Beta & $t$ & Beta & $t$ & Beta & $t$ & Beta & $t$ & Beta & $t$ & Beta & $t$ \\
\hline Age & 0.005 & 0.39 & 0.041 & 2.60 & -0.011 & 0.71 & -0.002 & 0.11 & 0.001 & 0.088 & 0.002 & 0.10 & -0.008 & -0.587 & -0.008 & 0.38 \\
\hline Gender & 0.012 & 0.93 & 0.038 & 2.34 & 0.084 & 5.54 & 0.025 & 1.58 & -0.006 & -0.393 & -0.029 & 1.74 & -0.056 & -3.99 & -0.001 & 0.69 \\
\hline Excitable & -0.260 & 17.37 & -0.260 & 14.14 & -0.069 & -4.02 & -0.342 & 18.98 & 0.074 & 4.02 & -0.012 & 0.63 & -0.131 & -8.19 & -0.157 & 9.01 \\
\hline Sceptical & -0.122 & 7.93 & -0.071 & 3.73 & 0.005 & 0.26 & -0.140 & 7.56 & -0.056 & 2.98 & 0.035 & 1.82 & 0.013 & 0.77 & -0.224 & 12.47 \\
\hline Cautious & -0.038 & 2.28 & -0.040 & 1.92 & -0.074 & 3.84 & -0.078 & 3.85 & 0.163 & 7.96 & -0.038 & 1.83 & -0.032 & 1.79 & -0.025 & 1.39 \\
\hline Reserved & -0.087 & 5.94 & -0.028 & 1.55 & -0.050 & 2.98 & 0.017 & 0.95 & -0.300 & 16.72 & 0.005 & 0.26 & 0.022 & 1.42 & -0.025 & 1.44 \\
\hline Leisurely & -0.046 & 3.14 & -0.017 & 0.97 & 0.008 & 0.477 & 0.035 & 1.99 & -0.036 & 2.01 & -0.092 & 5.02 & -0.025 & 1.63 & -0.047 & 2.74 \\
\hline Bold & 0.137 & 8.51 & 0.170 & 8.59 & 0.110 & 5.97 & 0.074 & 3.80 & 0.053 & 2.70 & -0.002 & 0.086 & 0.066 & 3.86 & 0.020 & 1.08 \\
\hline Mischievous & -0.293 & 18.98 & 0.20 & 1.03 & -0.027 & 1.53 & 0.028 & 1.51 & -0.110 & 5.82 & -0.228 & 11.75 & -0.477 & 28.91 & -0.163 & 9.02 \\
\hline Colourful & -0.053 & 3.16 & -0.058 & 2.79 & -0.062 & 3.18 & -0.132 & 6.49 & 0.131 & 6.32 & 0.038 & 1.77 & -0.074 & 4.12 & -0.001 & 0.03 \\
\hline Imaginative & -0.160 & 10.87 & -0.042 & 2.29 & -0.039 & 2.28 & 0.017 & 0.97 & -0.084 & 4.64 & -0.102 & 5.47 & -0.139 & 8.83 & -0.172 & 9.98 \\
\hline Diligent & 0.306 & 22.76 & 0.190 & 11.52 & 0.456 & 29.57 & 0.087 & 5.40 & -0.041 & 2.47 & 0.215 & 12.71 & 0.170 & 11.86 & 0.058 & 3.69 \\
\hline Dutiful & 0.095 & 6.92 & -0.005 & 0.27 & 0.046 & 2.91 & 0.132 & 7.97 & 0.132 & 7.81 & 0.010 & 0.055 & 0.015 & 1.06 & 0.036 & 2.25 \\
\hline$F(13,3498)$ & \multicolumn{2}{|c|}{219.70} & \multicolumn{2}{|c|}{$67.64^{* * *}$} & \multicolumn{2}{|c|}{$55.72^{* * *}$} & \multicolumn{2}{|c|}{$101.97^{* * *}$} & \multicolumn{2}{|c|}{$56.23^{* * *}$} & \multicolumn{2}{|c|}{$39.88^{* * *}$} & \multicolumn{2}{|c|}{$159.26^{* * *}$} & \multicolumn{2}{|c|}{$89.13^{* * *}$} \\
\hline Adj $R^{2}$ & \multicolumn{2}{|c|}{0.45} & \multicolumn{2}{|c|}{0.17} & \multicolumn{2}{|c|}{0.27} & \multicolumn{2}{|c|}{0.20} & \multicolumn{2}{|c|}{0.17} & \multicolumn{2}{|c|}{0.13} & \multicolumn{2}{|c|}{0.37} & \multicolumn{2}{|c|}{0.25} \\
\hline
\end{tabular}


indicated that between 13 and 37 percent of the variance was explained. In five of the seven regressions Diligent was a highly significant positive predictor while in three Mischievous was a highly negative predictor. The pattern for some facets, for instance Virtuous and Not Autonomous had a very different set of beta scores compared to the Domain Facet score.

Next the HDS eleven factors were subjected to a Varimax-rotated factor analysis (see Table 3). A three-fold factor solution emerged which is consistent with many other studies (Furnham et al., 2012), The First factor was labelled Moving Against, the second Moving Away and the third Moving Towards Others. These are identical to the usual DSM-IV-R three-fold classification called Dramatic, Emotional and Erratic (Cluster B), Odd and Eccentric (Cluster A), Anxious and Fearful (Cluster C).

The regressions were then repeated, this time using the higher order factor scores. Next, a regression was run on the three higher factors that result from the analysis of the HDS (see Table 4). The criterion variable was the total Prudence scale with the first step being sex and age and the second step being the higher order factors. The final regression was significant $(\mathrm{F}(5,5302)=1154.76, p<$ 0.001; $\operatorname{AdjR} 2=0.52$. All three factors were significant: Moving Against (Beta $=$ $-0.14, \mathrm{t}=9.84, p<0.001)$, Moving Away (Beta $=0.08, \mathrm{t}=5.56, p<0.001)$ and Moving Toward (Beta $=-0.71, \mathrm{t}=72.11, p<0.001)$.

The regressions in Table 4 show three things. First, although all the regressions were significant accounting for between $6 \%$ and $25 \%$ of the variance there were interesting differences between them. Second, all of the Beta's were significant and negative for Moving Away, while all were positive for Moving Toward others. Third, the regressions suggest the first two factors (Moralistic and Mastery) were more alike and different from the last two factors (Impulse Control and Avoids Trouble).

Table 3. Varimax Rotated Factor analysis of the HDS.

\begin{tabular}{|c|c|c|c|}
\hline & \multicolumn{3}{|c|}{ Component } \\
\hline Scales & Moving Against & Moving Away & Moving Toward \\
\hline Bold & 0.759 & 0.002 & 0.142 \\
\hline Mischievous & 0.734 & 0.046 & -0.148 \\
\hline Colourful & 0.730 & -0.277 & -0.095 \\
\hline Imaginative & 0.693 & 0.144 & -0.017 \\
\hline Excitable & 0.037 & 0.731 & -0.009 \\
\hline Reserved & -0.128 & 0.707 & -0.239 \\
\hline Cautious & -0.328 & 0.696 & 0.277 \\
\hline Leisurely & 0.211 & 0.583 & 0.319 \\
\hline Sceptical & 0.447 & 0.579 & 0.113 \\
\hline Diligent & 0.057 & 0.005 & 0.729 \\
\hline Dutiful & -0.149 & 0.081 & 0.724 \\
\hline Eigenvalue & 2.52 & 2.30 & 1.36 \\
\hline
\end{tabular}


Table 4. Regressions with prudence as criterion and higher order HDS factors as predictors.

\begin{tabular}{|c|c|c|c|c|c|c|c|c|c|c|c|c|c|c|c|c|}
\hline & \multicolumn{2}{|c|}{ Prudence } & \multicolumn{2}{|c|}{ Moralistic } & \multicolumn{2}{|c|}{ Mastery } & \multicolumn{2}{|c|}{ Virtuous } & \multicolumn{2}{|c|}{$\begin{array}{c}\text { Not } \\
\text { Autonomous }\end{array}$} & \multicolumn{2}{|c|}{$\begin{array}{c}\text { Not } \\
\text { spontaneous }\end{array}$} & \multicolumn{2}{|c|}{$\begin{array}{l}\text { Impulse } \\
\text { Control }\end{array}$} & \multicolumn{2}{|c|}{$\begin{array}{l}\text { Avoids } \\
\text { Trouble }\end{array}$} \\
\hline & Beta & $\mathrm{t}$ & Beta & $\mathrm{t}$ & Beta & $\mathrm{t}$ & Beta & $\mathrm{t}$ & Beta & $\mathrm{t}$ & Beta & $t$ & Beta & $t$ & Beta & $t$ \\
\hline Gender & 0.001 & 0.053 & 0.019 & 1.14 & 0.060 & 3.78 & -0.008 & 0.50 & 0.050 & 2.96 & -0.036 & 2.14 & -0.066 & 4.37 & 0.006 & 0.37 \\
\hline Age & 0.010 & 0.737 & 0.046 & 2.80 & -0.010 & -0.67 & 0.003 & 0.20 & 0.004 & 0.21 & -0.002 & 0.09 & -0.006 & 0.41 & 0.002 & 0.11 \\
\hline Against & -0.301 & 22.20 & 0.064 & 3.95 & 0.049 & 3.16 & -0.064 & 4.02 & -0.071 & 4.31 & -0.19 & 11.65 & -0.436 & 29.48 & -0.327 & 21.77 \\
\hline Away & -0.390 & 28.90 & -0.276 & 17.22 & -0.117 & 7.63 & -0.229 & 18.8 & -0.142 & 8.62 & -0.102 & 6.24 & -0.132 & 8.99 & -0.336 & 22.54 \\
\hline Towards & 0.341 & 25.14 & 0.144 & 8.90 & 0.385 & 24.91 & 0.150 & 9.36 & 0.171 & 10.3 & 0.156 & 9.50 & 0.202 & 13.67 & 0.055 & 3.69 \\
\hline $\begin{array}{c}\text { F } \\
\text { Statistic }\end{array}$ & \multicolumn{2}{|c|}{$\begin{array}{c}\mathrm{F}(5,3493)= \\
403.105 \\
p<0.001\end{array}$} & \multicolumn{2}{|c|}{$\begin{array}{c}\mathrm{F}(5,3493)= \\
80.66 \\
p<0.001\end{array}$} & \multicolumn{2}{|c|}{$\begin{array}{c}\mathrm{F}(5,3493)= \\
148.31 \\
p<0.001\end{array}$} & \multicolumn{2}{|c|}{$\begin{array}{c}\mathrm{F}(5,3492) \\
93.47 \\
p<0.001\end{array}$} & \multicolumn{2}{|c|}{$\begin{array}{c}\mathrm{F}(5,3490)= \\
44.86 \\
p<0.001\end{array}$} & \multicolumn{2}{|c|}{$\begin{array}{c}\mathrm{F}(5,3492)= \\
53.60 \\
p<0.001\end{array}$} & \multicolumn{2}{|c|}{$\begin{array}{c}\mathrm{F}(5,3492)= \\
228.75 \\
p<0.001\end{array}$} & \multicolumn{2}{|c|}{$\begin{array}{c}\mathrm{F}(5,3492)= \\
202.43 \\
p<0.001\end{array}$} \\
\hline $\operatorname{Adj}^{2}$ & \multicolumn{2}{|c|}{0.37} & \multicolumn{2}{|c|}{0.10} & \multicolumn{2}{|c|}{0.17} & \multicolumn{2}{|c|}{0.12} & \multicolumn{2}{|c|}{0.06} & \multicolumn{2}{|c|}{0.07} & \multicolumn{2}{|c|}{0.25} & \multicolumn{2}{|c|}{0.22} \\
\hline
\end{tabular}

a. Items in bold highlight $\mathrm{t}$ values $>10.00$. Beta's $>0.06, p<0.001$.

\subsection{Discussion}

The results suggest that the dark side traits (sub-clinical PDs) can account for as much as ten percent of the variance in explaining the Prudence Domain factor as well as the four facets. Inevitably it was Diligent at the PD item level that was the strongest correlate. Results suggest that Excitable (Borderline), Mischievous (Anti-Social) and Imaginative (Schizotypal) were all negatively correlated with the facets. However the pattern of results is most clear in Table 4 which demonstrates two of the higher order factors pf the HDS are most clearly, and nearly equally, related to both the domain and facet scores. Moving Against Factor (called Dramatic, Emotional and Erratic in DSM) and Moving Away (called Odd and Eccentric in DSM) tended to be negatively associated with the Prudence Domain and its facets.

This finding merits replication with a different criterion variable and a different sample.

\section{Study 2}

This study looks at the dark side correlates of the NEO-PI-R trait conscientiousness and its six facets. It attempted to replicate the findings of the first study also based on a large adult sample.

\subsection{Method}

\subsubsection{Participants}

In total 5726 British working adults took part in this study of which 1213 were females and 4513 males. Their mean age was 42.36 years ( $\mathrm{SD}=7.12$ years) with the range being between 23 and 65 years. They were nearly all (over 95\%) graduates and in middle class occupations with English as their mother tongue. 


\subsubsection{Materials}

NEO Personality Inventory - Revised (NEO-PI-R; Costa \& McCrae, 1992). This 240-item, non-timed questionnaire measures 30 primary personality traits (facets) and the underlying "Big Five" personality factors (domains). Items involve questions about typical behaviours or reactions, which are answered on a five-point Likert scale, ranging from "strongly disagree" to "strongly agree". The manual shows impressive indices of reliability and validity.

Hogan Development Survey (Hogan \& Hogan, 2007). See above

\subsubsection{Procedure}

As above but the data were obtained from a different consultancy.

\subsection{Results}

Table 5 shows the correlations between gender, age, social desirability and all the HDS PDs and the $\mathrm{C}$ domain and facet scores. All regressions were significant accounting for between $18 \%$ and $37 \%$ of the variance. Again, and as expected, Diligent was the factor that was most closely associated with all seven criterion variables. Gender, age and social desirability showed familiar results (females more than males, older more than younger and higher more than lower dissimulators) tended to have higher scores, though the effect sizes were small. Three other factors seemed consistently related to the $\mathrm{C}$ scores and it showed Excitable and Cautious individuals tend to score low, while Bold individuals score high.

Next the HDS eleven factors were subjected to a Varimax-rotated factor analysis (see Table 6). A three-fold factor solution emerged which is consistent to many other studies (Furnham et al., 2012). It was essentially identical to that shown in Table 4. The First factor was labelled Moving Against, the second Moving Away, and the third Moving Towards Others.

The regressions were then repeated, this time using the higher order factors. Table 7 shows the regression with the three higher order HDS factors. All three factors were significant predictors at Domain and Facet level. The Moving Away from People factor was the most consistent and powerful correlate. The Moving Towards other People was also significant for four of the six Facets. The Moving Against People factor was significant negative predictor on five analyses, but positive on two others, particularly N5 Impulsivity. The pattern was similar across the seven analyses: Moving Away was always negatively, and Moving Towards always positively associated with the $\mathrm{C}$ facets, while for Moving Against the association was less strong and mostly positive but negative for one of the regressions (C6). The pattern of results was broadly similar for C and C5.

\subsection{Discussion}

The results of this study show that many of the PDs are systematically related to $\mathrm{C}$ at the domain and facet level, partly because the facets are closely related and not orthogonal, Table 5 shows over 20 correlations of $r>0.20$. People with high $\mathrm{C}$ scores tend to be Diligent and Bold but low on Cautious. They also tend to 


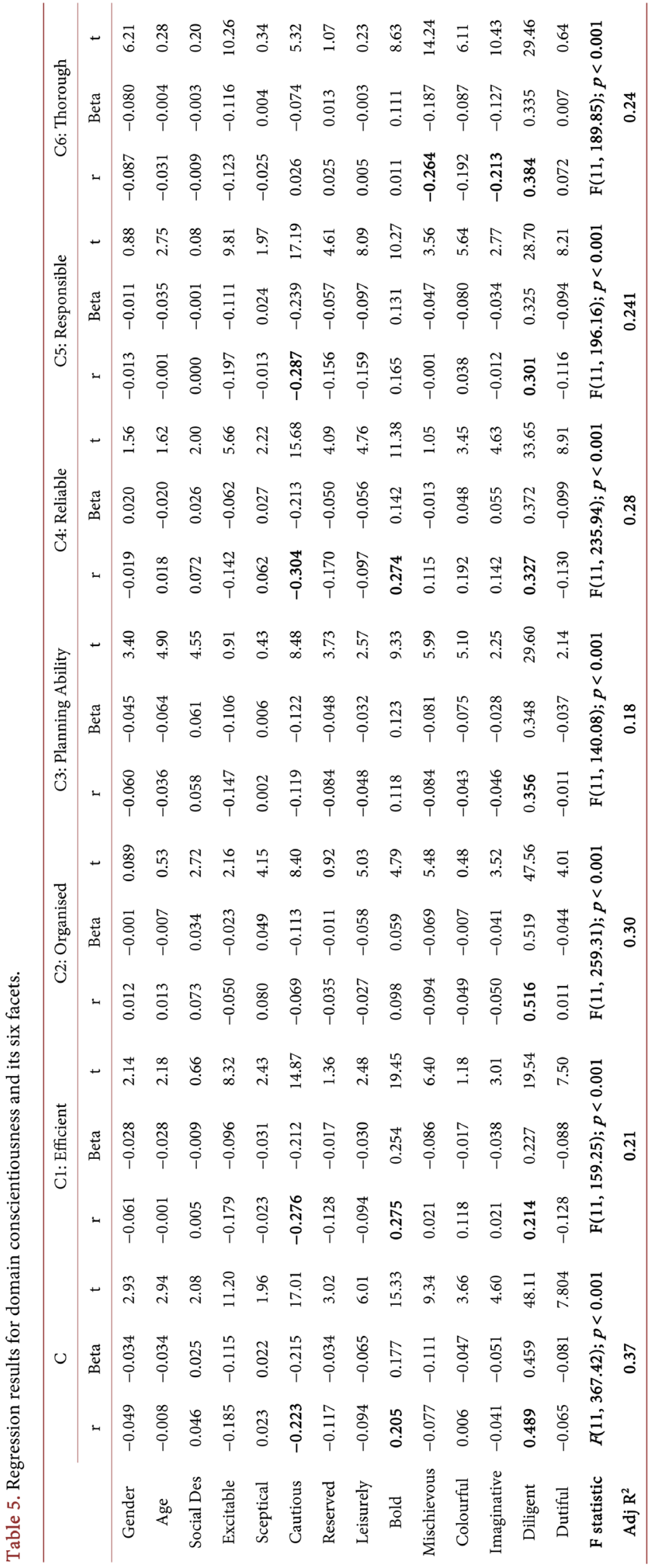


Table 6. Results from a VARIMAX rotated factor analysis of the HDS.

\begin{tabular}{cccc}
\hline & & Component & Moving Toward \\
\cline { 2 - 4 } Bold & Moving Against & Moving Away & 0.115 \\
Mischievous & 0.728 & 0.003 & -0.227 \\
Colourful & 0.725 & -0.001 & -0.100 \\
Imaginative & 0.722 & -0.330 & -0.070 \\
Reserved & 0.673 & 0.052 & -0.194 \\
Cautious & -0.228 & 0.716 & 0.260 \\
Leisure & -0.377 & 0.658 & 0.299 \\
Skeptical & 0.158 & 0.607 & 0.138 \\
Excitable & 0.447 & 0.584 & -0.059 \\
Diligent & -0.015 & 0.547 & 0.724 \\
Dutiful & 0.008 & 0.089 & 0.709 \\
Eigenvalue & -0.171 & -0.024 & 1.18 \\
Variance & 2.72 & 1.99 & 10.67 \\
\hline
\end{tabular}

Table 7. Regressions of the higher order HDS factors onto domain conscientiousness and the six facets.

\begin{tabular}{|c|c|c|c|c|c|c|c|c|c|c|c|c|c|c|}
\hline & \multicolumn{2}{|c|}{$\mathrm{C}$} & \multicolumn{2}{|c|}{$\mathrm{C} 1$} & \multicolumn{2}{|c|}{$\mathrm{C} 2$} & \multicolumn{2}{|c|}{$\mathrm{C} 3$} & \multicolumn{2}{|c|}{$\mathrm{C} 4$} & \multicolumn{2}{|c|}{ C5 } & \multicolumn{2}{|c|}{ C6 } \\
\hline & Beta & $\mathrm{t}$ & Beta & $\mathrm{t}$ & Beta & $\mathrm{t}$ & Beta & $\mathrm{t}$ & Beta & $\mathrm{t}$ & Beta & $\mathrm{t}$ & Beta & $\mathrm{t}$ \\
\hline Gender & -0.058 & 4.31 & -0.051 & 3.63 & -0.022 & 2.59 & -0.045 & 3.23 & -0.001 & 0.11 & -0.032 & 2.27 & -0.097 & 7.12 \\
\hline Age & 0.058 & 4.30 & 0.047 & 3.33 & 0.012 & 0.86 & 0.118 & 8.46 & 0.023 & 1.68 & 0.038 & 2.68 & 0.034 & 2.48 \\
\hline Against & 0.082 & 6.20 & 0.169 & 12.37 & 0.027 & 1.97 & 0.020 & 1.47 & 0.281 & 21.22 & 0.090 & 6.57 & -0.182 & 13.66 \\
\hline Away & -0.204 & 15.46 & -0.230 & 16.93 & -0.054 & 4.06 & -0.139 & 10.25 & -0.213 & 16.17 & -0.243 & 17.83 & -0.047 & 3.57 \\
\hline Towards & 0.305 & 23.06 & 0.097 & 7.12 & 0.340 & 25.26 & 0.258 & 19.00 & 0.143 & 10.81 & 0.138 & 10.08 & 0.308 & 23.18 \\
\hline $\begin{array}{c}\mathbf{F} \\
\text { Statistics }\end{array}$ & \multicolumn{2}{|c|}{$\begin{array}{c}\mathrm{F}(5,4922)= \\
164.85 \\
p<0.001\end{array}$} & \multicolumn{2}{|c|}{$\begin{array}{c}\mathrm{F}(5,4914)= \\
101.53 \\
p<0.001\end{array}$} & \multicolumn{2}{|c|}{$\begin{array}{c}\mathrm{F}(5,4913)= \\
131.56 ; \\
p<0.001\end{array}$} & \multicolumn{2}{|c|}{$\begin{array}{c}\mathrm{F}(5,4913)= \\
106.88 \\
p<0.001\end{array}$} & \multicolumn{2}{|c|}{$\begin{array}{c}\mathrm{F}(5,4913)= \\
165.88 \\
p<0.001\end{array}$} & \multicolumn{2}{|c|}{$\begin{array}{c}\mathrm{F}(5,4913)= \\
93.67 \\
p<0.001\end{array}$} & \multicolumn{2}{|c|}{$\begin{array}{c}\mathrm{F}(5,4913)= \\
159.13 ; \\
p<0.001\end{array}$} \\
\hline $\operatorname{Adj}^{2}$ & \multicolumn{2}{|c|}{0.14} & \multicolumn{2}{|c|}{0.09} & \multicolumn{2}{|c|}{0.12} & \multicolumn{2}{|c|}{0.10} & \multicolumn{2}{|c|}{0.14} & \multicolumn{2}{|c|}{0.09} & \multicolumn{2}{|c|}{0.14} \\
\hline
\end{tabular}

have low Excitable, Reserved, Leisurely and Imaginative scores. The PDs actually accounted for over a third of the variance suggesting a dark side to C. High C scorers at both domain and facet level tend to be, in DSM terminology, to be mainly Anxious and Fearful (and a little Dramatic, Emotional and Erratic) but not Odd and Eccentric.

\section{General Discussion}

The analyses in these two studies were broadly similar. Comparing Table 4 and Table 7 it seems the HDS scales accounted for more of the variance with the Prudence of the HPI measure than the C measure of the NEO-PI-R. Indeed at the Domain level the Dark Side factors accounted for nearly three times the variance ( $37 \%$ vs $14 \%$ ). Equally some facets of both scales (HPI: Not Autonomous, 
HPI; Not Spontaneous, NEO: Efficient, NEO: Responsible) did not seem related to the dark side factors while other (HPI: Impulse Control; HPI Avoids Trouble; NEO Reliable) were. Second, consistently throughout the analyses it was Diligent (OCD) that was most strongly related to the Domain and Facet scores from both instruments, particularly the NEO-PI-R measure. Third, the correlations and regressions suggested few major similarities and differences: for both analyses (see Table 1 and Table 5) Excitable and Diligent were strong predictors, while Bold seemed much more consistently a positively related to the facets of the NEO compared to the HPI. The HPI scales of Moralistic and Virtuous seem very different from the NEO scales which do not have this ethical component.

Table 3 and Table 6 show the results of the factor analyses of both data sets. The results are extremely consistent and in accordance with nearly all other studies in the area. This suggests that using the higher order factors may be a more reliable way of inspecting the results.

Comparing Table 4 and Table 7, these results show both similarities and differences. Similarities include the fact that the analyses of facets accounted for between $6 \%$ and $25 \%$ of the variance; there is a small but consistent sex and age effect showing females, and older people score higher than males and younger people; all the beta for Moving Away were negative, and most Moving Towards positive. The biggest difference between the two operationalisations of $\mathrm{C}$ lay in Moving Against people analysis where most Betas for Prudence/C (according to the NEO-PI-R) were mainly negative while in Table 7 they were all with one exception positive and often large. This suggests a rather important difference in the conception of the two measures of C. The Moving Against factor is associated with leadership behaviours, because bright, charismatic and self-confident people tend to be noticed.

Most of the results are to be expected, especially the relationship between OCD and C. What is perhaps most interesting and unpredictable is the consistent positive relationship between Bold and C. An inspection of the DSM manuals and the HDS manual would suggest, if anything that Bold (narcissistic) individuals would be very low on $\mathrm{C}$. High scorers tend to be demanding and overbearing, self-promoting and with little sense of team loyalty. Most importantly, Boldness is associated with an over-estimation of talents and accomplishments, a strong sense of entitlement and extra-punativeness. It seems that Bold Narcissists over-report their $\mathrm{C}$ either because they genuinely believe they are hard-working. However sub-clinical Narcissism, may be more related to achievement motivation which means they can be brave and happy to courageously put forward their ideas and want their work recognised and rewarded.

There is an interesting paradox in these findings which is that whilst $\mathrm{C}$ is thought of as essential in work and leadership success many papers have suggested that Moving Against variables are also associated with speed of promotion (Furnham et al., 2013) and positive ratings of management potential (Furnham et al. 2012). Thus while Diligence has been shown to be a desirable 
characteristic it is not strongly associated with success at work. The literature in this field (Furnham, 2015) all suggests an optimal, curvilinear association between the dark side variables and success which is clearly the case with Diligence: a very high score might indicate subliminal OCD while a low score indicates poor organisation, planning and reliability. Indeed there are various papers connecting diligence with perfectionism which has shown to be correlated as much as $r=0.50$ (Stairs et al. 2012; Stoeber, Otto, \& Dalkbert, 2009).

These results suggest that people eager to use a $\mathrm{C}$ scale for assessment and selection would do well to consider subtle differences between various measures. It is also important to use subscale scores and think of the implications of extreme (very high or low) scorers, and the potential dark or down side of Conscientiousness.

This study was a cross-sectional study based on self-report with inevitable consequences of method-invariance and the inability to demonstrate causal relations. It would have been very desirable to have behavioural measures of work success and to examine their relationship to those who scored two standard deviations above and below the mean on domain and facet scales measuring

\section{Conclusion}

The literature on the many correlates (education, health, wealth) of personality traits nearly all implicate Conscientiouness as perhaps the most important of the Big Five. Being planful, organized, hard-working, reliable and responsible has many benefits. This study however chose to establish whether there was a dark-side to conscientiousness particular at high levels. Some results were highly predictable that those who were very diligent and therefore exhibiting sub-clinical OCD scored very high. However less predictable was the fact that Bold, sub-clinical narcissists were, or claimed to be conscientiousness.

There are a number of implications of the study. Firstly, as have been noted many times before extremes of a healthy trait tend to indicate poor health. Secondly, for those in hiring it is obvious to look for people who are organized and hard-working, yet possibly overlook the point that very high scores may indicate pathology.

An interesting academic point refers to the extent to which the findings were replicated in two different but related measures of conscientiousness, particularly when examined at the facet level. Further research may consider the relation between the two conscientious measures, particularly at the facet level, to examine the convergent and divergent validity between them.

\section{References}

American Psychiatric Association (2013). Diagnostic and Statistical Manual of Mental Disorders (4th ed. Rev.). Washington, DC: APA.

https://doi.org/10.1176/appi.books.9780890425596

Bastiaansen, L., Rossi, G., \& De Fruyt, F. (2012). Comparing Five Sets of Five-Factor Model Personality Disorder Counts in a Heterogeneous Sample of Psychiatric Patients. 
European Journal of Personality, 27, 377-388. https://doi.org/10.1002/per.1859

Bastiaansen, L., Rossi, G., Schotte, C., \& De Fruyt, F. (2011). The Structure of Personality Disorders. Journal of Personality Disorders, 25, 378-396. https://doi.org/10.1521/pedi.2011.25.3.378

Bollaert, H., \& Petit, V. (2010). Beyond the Dark Side of Executive Psychology. European Journal of Management, 28, 362-376. https://doi.org/10.1016/j.emj.2010.01.001

Carson, M., Shanock, L., Heggestad, E., Andrew, A., Pugh, S., \& Walter, M. (2012). The Relationship between Dysfunctional Interpersonal Tendencies, Derailment Potential Behavior and Turnover. Journal of Business and Psychology, 27, 291-304. https://doi.org/10.1007/s10869-011-9239-0

Carter, N., Dalal, D., Boyce, A., O’Connell, M., Kung, M-C., \& Delgado, K. (2014). Uncovering Curvilinear Relationships between Conscientiousness and Job Performance. Journal of Applied Psychology, 99, 564-586. https://doi.org/10.1037/a0034688

Costa Jr., P. T., \& McCrae, R. R. (1992). Revised NEO Personality Inventory (NEO-PI-R) and NEO Five-Factor Inventory (NEO-FFI) Professional Manual. Odessa, FL: Psychological Assessment Resources.

De Fruyt, F., De Clercq, B., Milley, J., Rolland, J. P., Jung, S. C., Taris, R., Furnham, A., \& Hiel, A. (2009). Assessing Personality at Risk in Personnel Selection and Development. European Journal of Personality, 23, 51-69. https://doi.org/10.1002/per.703

Fico, J., Hogan, R., \& Hogan, J. (2000). Interpersonal Compass Manual and Interpretation Guide. Tulsa, OK: Hogan Assessment System.

Furnham, A, \& Crump, J. (2005). Personality Traits, Types and Disorders. European Journal of Personality, 19, 167-184. https://doi.org/10.1002/per.543

Furnham, A. (2010). The Elephant in the Boardroom: The Psychology of Leadership Derailment. Bracknell: Palgrave MacMillan. https://doi.org/10.1057/9780230281226

Furnham, A. (2015). Backstabbers and Bullies. London: Bloomsbury.

Furnham, A., Crump, J., \& Ritchie, W. (2013). What It Takes: Ability, Demographic, Bright and Dark Side Correlates of Years to Promotion. Personality and Individual Differences, 55, 952-956. https://doi.org/10.1016/j.paid.2013.07.469

Furnham, A., Richards, S., \& Paulhus, D. (2013). The Dark Triad: A 10 Year Review. Social and Personality Psychology Compass, 7, 199-215.

https://doi.org/10.1111/spc3.12018

Furnham. A., Trickey, G., \& Hyde, G. (2012). Bright Aspects to Dark Side Traits: Dark Side Traits Associated with Work Success. Personality and Individual Differences, 52, 908-913. https://doi.org/10.1016/j.paid.2012.01.025

Hogan, R., \& Hogan, J. (2001). Assessing Leadership: A View from the Dark Side. International Journal of Selection and Assessment, 9, 40-51. https://doi.org/10.1111/1468-2389.00162

Hogan, R., \& Hogan, J. (2007). Hogan Personality Inventory Manual. Tulsa, OK: HAS.

Hogan, R., \& Hogan, J. (2009). Hogan Development Survey Manual. Tulsa, OK: HAS.

Howard, P. J., \& Howard, J. M. (2001). The Owner's Manual for Personality at Work. Austin, Atlanta: Bard Press.

Koutoufa, I., \& Furnham, A. (2014). Mental Health Literacy and Obsessive-Compulsive Personality Disorder. Psychiatry Research, 215, 223-228. https://doi.org/10.1016/j.psychres.2013.10.027

MacCann, C., Duckworth, A., \& Roberts, R. (2009). Empirical Identification of the Major Facets of Conscientiousness. Learning and Individual Differences, 19, 451-458.

https://doi.org/10.1016/j.lindif.2009.03.007 
Nettle, D. (2006). The Evolution of Personality Variation in Humans and Other Animals. American Psychologist, 61, 622-631. https://doi.org/10.1037/0003-066X.61.6.622

Roberts, B., Chernyshenko, O., Stark, S., \& Goldberg, L. (2005). The Structure of Conscientiousness. Personnel Psychology, 58, 103-139. https://doi.org/10.1111/j.1744-6570.2005.00301.x

Rolland, J. P., \& De Fruyt, F. (2003). The Validity of FFM Personality Dimensions and Maladaptive Traits to Predict Negative Affect at Work. European Journal of Personality, 17, 101-121. https://doi.org/10.1002/per.485

Samuel, D., \& Widiger, T. (2008). A Meta-Analytic Review of the Relationship between the Five-Factor Model and the DSM-IV-TR Personality Disorders. Clinical Psychology Review, 28, 1326-1342. https://doi.org/10.1016/j.cpr.2008.07.002

Saulsman, L., \& Page, A. (2004). The Five Factor Model and Personality Disorder Empirical Literature: A Meta-Analytic Review. Clinical Psychology Review, 23, 1055-1085. https://doi.org/10.1016/j.cpr.2002.09.001

Stairs, A., Smith, G., Zapolski, T., Combs, J., \& Settles, R. (2012). Clarifying the Construct of Perfectionism. Assessment, 19, 146-166. https://doi.org/10.1177/1073191111411663

Stoeber, J., Otto, K., \& Dalbert, C. (2009). Perfectionism and the Big Five. Personality and Individual Differences, 47, 363-368. https://doi.org/10.1016/j.paid.2009.04.004

Widiger, T. (2011). Integrating Normal and Abnormal Personality Structure: A Proposal for DSM-V. Journal of Personality Disorders, 25, 338-363.

https://doi.org/10.1521/pedi.2011.25.3.338

Widiger, T. A., Costa, P. T., \& McCrae, R. R. (2001). Proposals for Axis II: Diagnosing Personality Disorders Using the Five Factor Model. In P. T. Costa, \& T. A. Widiger (Eds.), Personality Disorders and the Five Factor Model of Personality (2nd ed., pp. 432-456). Washington DC: American Psychological Association.

Scientific Research Publishing

Submit or recommend next manuscript to SCIRP and we will provide best service for you:

Accepting pre-submission inquiries through Email, Facebook, LinkedIn, Twitter, etc. A wide selection of journals (inclusive of 9 subjects, more than 200 journals)

Providing 24-hour high-quality service

User-friendly online submission system

Fair and swift peer-review system

Efficient typesetting and proofreading procedure

Display of the result of downloads and visits, as well as the number of cited articles

Maximum dissemination of your research work

Submit your manuscript at: http://papersubmission.scirp.org/

Or contact psych@scirp.org 